Jin-Feng Chu*

\title{
The crystal structure of bis(isothiocyanato- $\left.\mathrm{K}^{1} \mathrm{~N}\right)-\left(\right.$ methanol- $\left.^{1} O\right)$-[2- morpholine-4-yl-4,6-di(pyrazol-1-yl)-1,3,5-triazine- $\left.\mathrm{K}^{3} N, N^{\prime}, N^{\prime \prime}\right]$ manganese(II), $\mathrm{C}_{16} \mathrm{H}_{18} \mathrm{MnN}_{10} \mathrm{O}_{2} \mathrm{~S}_{2}$
}
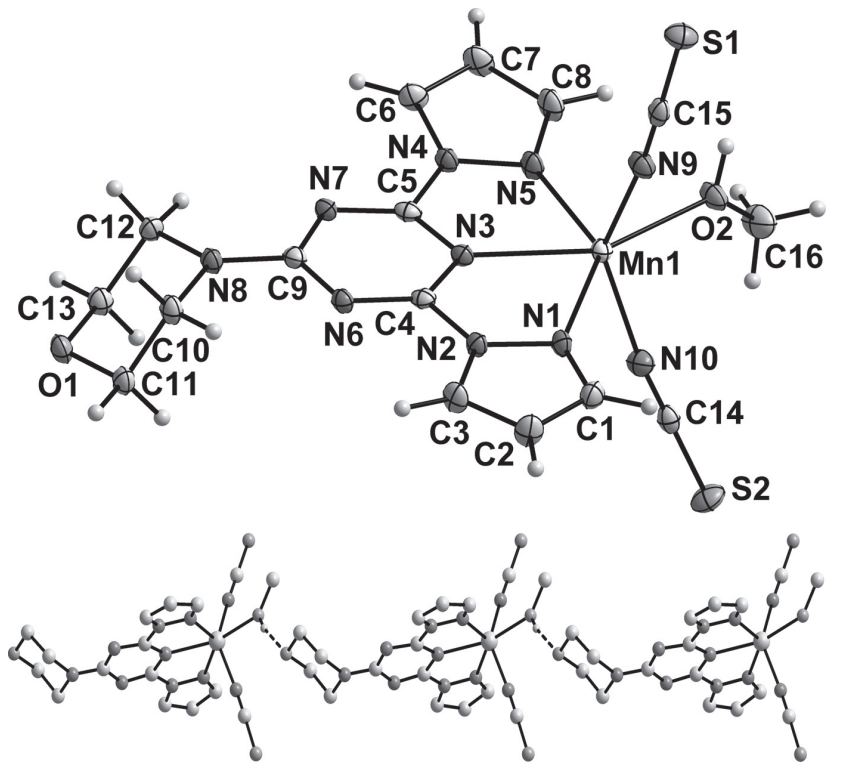

https://doi.org/10.1515/ncrs-2020-0161

Received March 26, 2020; accepted May 17, 2020; available online June 18,2020

\section{Abstract}

$\mathrm{C}_{16} \mathrm{H}_{18} \mathrm{MnN}_{10} \mathrm{O}_{2} \mathrm{~S}_{2}$, triclinic, $P \overline{1}$ (no. 2), $a=7.8738(7) \AA$, $b=12.012(2) \AA, \quad c=12.182(2) \AA \AA \quad \alpha=85.635(16)^{\circ}, \quad \beta=$ 81.077(14) $, \quad \gamma=74.540(14)^{\circ}, \quad V=1096.3(3) \AA^{3}, \quad Z=2$, $R_{\mathrm{gt}}(F)=0.0353, w R_{\mathrm{ref}}\left(F^{2}\right)=0.0896, T=96.5 \mathrm{~K}$.

CCDC no.: 2004283

Table 1 contains crystallographic data and Table 2 contains the list of the atoms including atomic coordinates and displacement parameters.

\section{Source of material}

2-Morpholine-4-yl-4,6-di(pyrazol-1-yl)-1,3,5-triazine (mpt) was prepared according to the literature [5]. A solution of mpt $(0.1 \mathrm{mmol}, 0.030 \mathrm{~g})$ in methanol $(2 \mathrm{~mL})$ was added to a

\footnotetext{
*Corresponding author: Jin-Feng Chu, State Key Laboratory of Chemical Resource Engineering, Beijing University of Chemical Technology, Beijing 100029, P.R. China, e-mail: chujf@mail.buct.edu.cn. https://orcid.org/0000-00032818-3630
}

Table 1: Data collection and handling.

\begin{tabular}{|c|c|}
\hline Crystal: & Colourless block \\
\hline Size: & $0.80 \times 0.30 \times 0.20 \mathrm{~mm}$ \\
\hline Wavelength: & Mo $K \alpha$ radiation $(0.71073 \AA$ ) \\
\hline$\mu:$ & $0.83 \mathrm{~mm}^{-1}$ \\
\hline Diffractometer, scan mode: & Xcalibur-Gemini, $\omega$ \\
\hline$\theta_{\max }$, completeness: & $26.0^{\circ},>99 \%$ \\
\hline$N(h k l)_{\text {measured }}, N(h k l)_{\text {unique }}, R_{\text {int }}:$ & $6937,4291,0.031$ \\
\hline Criterion for $I_{\mathrm{obs}}, N\left(h k l_{\mathrm{gt}}\right.$ : & $I_{\text {obs }}>2 \sigma\left(I_{\text {obs }}\right), 3706$ \\
\hline$N(\text { param })_{\text {refined }}$ & 284 \\
\hline Programs: & $\begin{array}{l}\text { CrysAlis }^{\text {PRO }}[1], \text { Olex2 [2], } \\
\text { SHELX }[3,4]\end{array}$ \\
\hline
\end{tabular}

Table 2: Fractional atomic coordinates and isotropic or equivalent isotropic displacement parameters $\left(\AA^{2}\right)$.

\begin{tabular}{lrrrr}
\hline Atom & $\boldsymbol{x}$ & $\boldsymbol{y}$ & $\boldsymbol{z}$ & $\boldsymbol{U}_{\text {iso }}{ }^{*} \boldsymbol{U}_{\text {eq }}$ \\
\hline C1 & $-0.1179(3)$ & $0.3320(2)$ & $0.37881(19)$ & $0.0205(5)$ \\
H1 & -0.1143 & 0.2544 & 0.3747 & $0.025^{*}$ \\
C2 & $-0.2647(3)$ & $0.4148(2)$ & $0.4309(2)$ & $0.0239(5)$ \\
H2A & -0.3722 & 0.4027 & 0.4661 & $0.029^{*}$ \\
C3 & $-0.2163(3)$ & $0.5162(2)$ & $0.41887(19)$ & $0.0216(5)$ \\
H3 & -0.2846 & 0.5877 & 0.4443 & $0.026^{*}$ \\
C4 & $0.0566(3)$ & $0.56854(19)$ & $0.32625(17)$ & $0.0139(4)$ \\
C5 & $0.3093(3)$ & $0.59727(19)$ & $0.23619(17)$ & $0.0148(4)$ \\
C6 & $0.6226(3)$ & $0.5949(2)$ & $0.15773(19)$ & $0.0209(5)$ \\
H6 & 0.6233 & 0.6710 & 0.1668 & $0.025^{*}$ \\
C7 & $0.7625(3)$ & $0.5082(2)$ & $0.1168(2)$ & $0.0247(5)$ \\
H7 & 0.8782 & 0.5130 & 0.0919 & $0.030^{*}$ \\
C8 & $0.6974(3)$ & $0.4096(2)$ & $0.1196(2)$ & $0.0236(5)$ \\
H8 & 0.7658 & 0.3375 & 0.0959 & $0.028^{*}$ \\
C9 & $0.0998(3)$ & $0.74670(19)$ & $0.31087(17)$ & $0.0149(4)$ \\
C10 & $-0.1341(3)$ & $0.90944(19)$ & $0.39280(18)$ & $0.0186(5)$ \\
H10A & -0.1205 & 0.9537 & 0.4527 & $0.022^{*}$ \\
H10B & -0.1877 & 0.8483 & 0.4251 & $0.022^{*}$ \\
C11 & $-0.2513(3)$ & $0.98643(19)$ & $0.31675(19)$ & $0.0196(5)$ \\
H11A & -0.2694 & 0.9411 & 0.2591 & $0.024^{*}$ \\
H11B & -0.3665 & 1.0209 & 0.3585 & $0.024^{*}$ \\
C12 & $0.1249(3)$ & $0.94790(19)$ & $0.27484(19)$ & $0.0187(5)$ \\
H12A & 0.2350 & 0.9114 & 0.2290 & $0.022^{*}$ \\
H12B & 0.1527 & 0.9913 & 0.3305 & $0.022^{*}$ \\
C13 & $-0.0002(3)$ & $1.0289(2)$ & $0.20327(18)$ & $0.0194(5)$ \\
H13A & 0.0519 & 1.0911 & 0.1722 & $0.023^{*}$ \\
H13B & -0.0154 & 0.9870 & 0.1421 & $0.023^{*}$ \\
C14 & $0.1349(3)$ & $0.26710(19)$ & $0.03082(18)$ & $0.0165(5)$ \\
C15 & $0.4709(3)$ & $0.22243(19)$ & $0.45325(19)$ & $0.0179(5)$ \\
C16 & $0.5965(3)$ & $0.1343(2)$ & $0.0441(2)$ & $0.0331(6)$ \\
& & & & \\
H6 & & & &
\end{tabular}

Ә Open Access. @ 2020 Jin-Feng Chu, published by De Gruyter. (c) BY This work is licensed under the Creative Commons Attribution 4.0 International License. 
Table 2 (continued)

\begin{tabular}{lrrrr}
\hline Atom & $\boldsymbol{x}$ & $\boldsymbol{y}$ & $\boldsymbol{z}$ & $\boldsymbol{U}_{\text {iso }} \boldsymbol{U}_{\text {eq }}$ \\
\hline H16A & 0.6846 & 0.1676 & 0.0008 & $0.050^{*}$ \\
H16B & 0.4932 & 0.1497 & 0.0070 & $0.050^{*}$ \\
H16C & 0.6442 & 0.0523 & 0.0527 & $0.050^{*}$ \\
Mn1 & $0.31874(4)$ & $0.33195(3)$ & $0.22784(3)$ & $0.01446(11)$ \\
N1 & $0.0134(2)$ & $0.37752(15)$ & $0.33668(15)$ & $0.0158(4)$ \\
N2 & $-0.0476(2)$ & $0.49210(15)$ & $0.36209(14)$ & $0.0146(4)$ \\
N3 & $0.2144(2)$ & $0.52009(15)$ & $0.26725(14)$ & $0.0141(4)$ \\
N4 & $0.4804(2)$ & $0.54796(16)$ & $0.18301(15)$ & $0.0162(4)$ \\
N5 & $0.5254(2)$ & $0.43271(16)$ & $0.16038(15)$ & $0.0182(4)$ \\
N6 & $-0.0065(2)$ & $0.67686(15)$ & $0.35332(14)$ & $0.0147(4)$ \\
N7 & $0.2646(2)$ & $0.70880(15)$ & $0.25099(14)$ & $0.0145(4)$ \\
N8 & $0.0401(2)$ & $0.85940(15)$ & $0.32927(15)$ & $0.0162(4)$ \\
N9 & $0.4094(2)$ & $0.25665(16)$ & $0.37471(16)$ & $0.0199(4)$ \\
N10 & $0.1872(2)$ & $0.29567(17)$ & $0.10488(15)$ & $0.0197(4)$ \\
01 & $-0.17079(19)$ & $1.07687(13)$ & $0.26627(13)$ & $0.0201(3)$ \\
O2 & $0.5484(2)$ & $0.18365(14)$ & $0.15060(13)$ & $0.0233(4)$ \\
H2 & $0.632(2)$ & $0.161(2)$ & $0.1898(14)$ & $0.027^{*}$ \\
S1 & $0.55860(8)$ & $0.17609(5)$ & $0.56665(5)$ & $0.02377(15)$ \\
S2 & $0.06147(8)$ & $0.22747(6)$ & $-0.07341(5)$ & $0.02541(15)$ \\
\hline
\end{tabular}

solution of $\mathrm{MnCl}_{2} \cdot 4 \mathrm{H}_{2} \mathrm{O}(0.1 \mathrm{mmol}, 0.020 \mathrm{~g})$ in methanol $(5 \mathrm{~mL})$, and then an excess of a solution of potassium thiocyanate in methanol $(2 \mathrm{~mL})$ was added. The mixture was filtered and the filtrate was set aside to crystallize at ambient temperature. Colourless crystals of the title compound were obtained.

\section{Experimental details}

A suitable single crystal was mounted onto the end of a thin glass fiber using Fomblin oil. C-bound $\mathrm{H}$ atoms were geometrically placed $(\mathrm{C}-\mathrm{H}=0.93-0.97 \AA)$ and refined as riding with $U_{\text {iso }}(\mathrm{H})=1.2-1.5 U_{\text {eq }}(\mathrm{C})$. The O-bound $\mathrm{H}$-atom was located in a difference Fourier map but was refined with a distance restraint $\mathrm{O}-\mathrm{H}=0.85 \pm 0.01 \AA$, and with $U_{\text {iso }}(\mathrm{H})$ set to $1.5 U_{\text {eq }}(0)$.

\section{Comment}

In the past decades, the crystal materials of supramolecular complexes have attracted great interest due to their potential applications in several fields [6-8]. The structure design and synthesis of new manganese complexes are of general interest and beneficial to the research of magnetic materials $[9,10]$. In the course of our efforts to explore new supramolecular architectures using mpt [11] and $\mathrm{NCS}^{-}$ligands, the title compound was successfully synthesized and determined by single-crystal X-ray analysis.

The molecular unit comprises one Mn(II) cation, one mpt ligand, two $\mathrm{NCS}^{-}$anions and one methanol ligand. Each
$\mathrm{Mn}(\mathrm{II})$ center is six-coordinated with a distorted octahedral environment by five $\mathrm{N}$ atoms and one $\mathrm{O}$ atom. The bond lengths and angles within structure are unexceptional. In details, the $\mathrm{Mn}-\mathrm{N}$ bond lengths range from 2.0802(18) to 2.5015(18) $\AA$, and the $\mathrm{Mn}-\mathrm{N}_{\mathrm{mpt}}$ bond distances are longer than the $\mathrm{Mn}-\mathrm{N}_{\mathrm{NCS}}$ distances. The $\mathrm{Mn}-\mathrm{O}$ bond length is 2.3105(17) A. The bond angles around Mn(II) range from $67.21(6)^{\circ}$ to $148.98(6)^{\circ}$.

As seen from the lower view of the figure, the adjacent molecular units are linked by the intermolecular $\mathrm{O}-\mathrm{H} \cdots \mathrm{O}$ hydrogen-bond $\left[\mathrm{O} 2-\mathrm{H} 2 \cdots \mathrm{O} 1^{\mathrm{i}}: \mathrm{H} 2 \cdots \mathrm{O} 1^{\mathrm{i}}=1.94 \AA\right.$, $02 \cdots \mathrm{O} 1^{\mathrm{i}}=2.7747(22) \AA$ with angle at $\mathrm{H} 2=167.6^{\circ}$ for (i) $x+1$, $y-1, z]$, and the one-dimensional chain is formed.

Acknowledgements: This work was supported by the Fundamental Research Funds for the Central Universities (XK1802-6).

\section{References}

1. Agilent Technologies: CrysAlis ${ }^{\text {Pro }}$. Agilent Technologies, Version 1.171.35.11. Agilent Technologies UK Ltd, Oxford, UK (2011).

2. Dolomanov, O. V.; Bourhis, L. J.; Gildea, R. J.; Howard, J. A. K.; Puschmann, H.: OLEX2: a complete structure solution, refinement and analysis program. J. Appl. Crystallogr. 42 (2009) 339-341.

3. Sheldrick, G. M.: A short history of SHELX. Acta Crystallogr. A64 (2008) 112-122.

4. Sheldrick, G. M.: SHELXL-97, Program for the Refinement of Crystal Structures. University of Göttingen, Göttingen, Germany (1997).

5. Chen, W.; Chu, J. F.; Wang, Y. Q.: Synthesis, characterization and preliminary reactivity behaviors with transitional metals of a new polydentate $N$-donor ligand. J. Mol. Struct. 1068 (2014) 237-244.

6. Zhang, Y.; Ali, B.; Wu, J.; Guo, M.; Yu, Y.; Tang, J.; Zhang, Y.; Liu, Z.; Tang, J.: Construction of metallosupramolecular coordination complexes: from lanthanide helicates to octahedral cages showing single-molecule magnet behavior. Inorg. Chem. 58 (2019) 3167-3174.

7. Freire, C.; Nunes, M.; Pereira, C.; Fernandes, D. M.; Peixoto, A. F.; Rocha, M.: Metallo(salen) complexes as versatile building blocks for the fabrication of molecular materials and devices with tuned properties. Coord. Chem. Rev. 394 (2019) 104-134.

8. Wang, A.; Fan, R.; Dong, Y.; Chen, W.; Song, Y.; Wang, P.; Hao, S.; Liu, Z.; Yang, Y.: (E)-4-Methyl-N-((quinolin-2yl)ethylidene)aniline as ligand for IIB supramolecular complexes: synthesis, structure, aggregation-induced emission enhancement and application in PMMA-doped hybrid material. Dalton Trans. 46 (2017) 71-85.

9. Bohuslav, D.; Radovan, H.; Zdeneěk, T.: Structural and magnetic properties of heptacoordinated $\mathrm{Mn}^{\text {" }}$ complexes containing a 15-membered pyridine-based macrocycle and halido/ pseudohalido axial coligands. RSC Adv. 6 (2016) 34674-34684. 
10. Neumann, T.; Gallo, G.; Dinnebier, R. E.; Näther, C.: Synthesis, crystal structures, and properties of $\mathrm{Mn}(\mathrm{NCS})_{2}$ coordination compounds with 4-picoline as coligand and crystal structure of $\mathrm{Mn}(\mathrm{NCS})_{2}$. Z. Anorg. Allg. Chem. 646 (2020) 88-94.
11. Chu, J.-F.; Zhang, M.-Y.; Wang, Y.-Q.: Syntheses, crystal structures, and properties of three copper(II) complexes constructed by 4-(4,6-bis(1H-pyrazol-1-yl)-1,3,5-triazin-2-yl)morpholine. Z. Anorg. Allg. Chem. 643 (2017) 1101-1106. 